\title{
desenvolvimento $\mathrm{Am}$ QUESTÂOO
}

\section{O Uso de Recursos Estratégicos na Produção de Orgânicos O Caso dos Produtores da Feira Ecológica de Passo Fundo-RS}

http://dx.doi.org/10.21527/2237-6453.2019.48.312-333

Recebido em: 19/6/2018

Aceito em: 19/3/2019

\section{Ana Claudia Machado Padilha, ${ }^{1}$ Jordana Eidelwein, ${ }^{2}$ Antônio Genésio Vasconcelos Neto, ${ }^{3}$ Adriana Carvalho Pinto Vieira, ${ }^{4}$ Marcelino de Souza ${ }^{5}$}

\begin{abstract}
RESUMO
A pesquisa tem como objetivo identificar os recursos estratégicos tangíveis e intangíveis utilizados na produção de orgânicos por agricultores da Feira Ecológica de Passo Fundo-RS. Em termos metodológicos, foi realizada uma pesquisa exploratória e qualitativa, tendo como população-alvo os produtores de orgânicos da Feira Ecológica de Passo Fundo. Foram pesquisados seis produtores, utilizando o critério de saturação, a partir de critérios de seleção que responderam ao questionário, elaborado a partir da literatura da Visão Baseada em Recursos (VBR). As respostas foram analisadas utilizando a técnica de análise de conteúdo. Como resultados significativos pode-se destacar que os recursos tangíveis e intangíveis são elementos fundamentais para o sucesso da atividade de produção de orgânicos, com destaque especial para a instituição cooperativa, com a função de congregar os produtores, viabilizar o canal de comercialização e, especialmente, oferecer mecanismos de certificação da produção orgânica.
\end{abstract}

Palavras-chave: Visão baseada em recursos. Produção orgânica. Agricultura familiar.

THE USE OF STRATEGIC RESOURCES IN THE PRODUCTION OF ORGANICS:

THE CASE OF THE PRODUCERS OF THE ECOLOGICAL FAIR OF PASSO FUNDO-RS

\begin{abstract}
The research aims to identify the tangible and intangible resources that are configured as strategic in the organic production of the farmers of the Passo Fundo-RS Ecological Fair. Methodologically, an exploratory and qualitative research was carried out, with the target population being the organic producers of the Passo Fundo Ecological Fair, six producers were surveyed using the saturation criterion based on selection criteria that answered the questionnaire, from the Resource Based View (RBV) literature that were analyzed using the content analysis technique. As significant results, it can be highlighted that tangible and intangible resources are fundamental elements for the success of the organic production activity, with special emphasis on the cooperative institution that has the function of assembling the producers, making feasible the commercialization channel and, especially, to offer certification mechanisms for organic production.
\end{abstract}

Keywords: Resource based view. Organic production. Family farming.

\footnotetext{
${ }^{1}$ Doutora em Agronegócios pela Universidade Federal do Rio Grande do Sul (UFRGS). Professora da Universidade de Passo Fundo (UPF). anapadilha@upf.br

${ }^{2}$ Graduada em Administração pela Universidade de Passo Fundo (UPF).adm.jordana@gmail.com

${ }^{3}$ Doutor em Administração de Empresas pela Fundação Getúlio Vargas (FGV-SP). Analista da Embrapa Agroindústria Tropical, Fortaleza. genesio.vasconcelos@embrapa.br

${ }^{4}$ Doutora em Desenvolvimento Econômico pela Universidade Estadual de Campinas (Unicamp). Pesquisadora colaboradora da Universidade Federal do Estado do Rio de Janeiro (Unirio). dricpvieira@gmail.com

${ }^{5}$ Doutor em Engenharia Agrícola pela Universidade Estadual de Campinas (Unicamp). Professor da Universidade Federal do Rio Grande do Sul (UFRGS).marcelino.souza@uol.com.br
} 
A tendência mundial de aumento da demanda em busca de produtos e serviços que contribuem para a saúde e o bem-estar é acompanhada pelo crescimento do mercado de produtos naturais e orgânicos. Este crescimento e transformação de mercado estão predominantemente associados aos valores de sustentabilidade, saúde, legitimidade, certificação e segurança ambiental (DIAS et al., 2015).

No Brasil, a agricultura orgânica teve início na década de 70 do século 20, mas apenas em 1980 as técnicas foram difundidas no campo e, a partir de 1992, após a Conferência das Nações Unidas para o Meio Ambiente e o Desenvolvimento (ECO-92), os produtos orgânicos adquiriram expressividade comercial, conquistando espaço em supermercados e feiras livres, atraindo um maior número de consumidores (PEREIRA et al., 2008).

Como consequência da demanda por alimentos orgânicos percebe-se oportunidades de criação de novos negócios para os diversos segmentos da agropecuária nacional. O mercado global de orgânicos movimenta cerca de US\$ 72 bilhões/ano (SANTOS, 2015). Segundo a Sociedade Nacional da Agricultura - SNA (2014), o crescimento do mercado no Brasil de produtos saudáveis vem crescendo nos últimos dois anos, na porcentagem de $30 \%$ a $40 \%$.

De acordo com Pereira et al. (2008), os produtos orgânicos são aqueles, de origem vegetal ou animal, livres de agrotóxicos ou qualquer outro tipo de produtos químicos utilizados no seu processo de produção, produzidos mediante técnicas de cultivo que primam pelo estabelecimento do equilíbrio ecológico no sistema agrícola. Segundo os autores, essa é uma tendência mundial, que ocorre também no Brasil, impulsionada pelo crescimento do consumo de alimentos produzidos com menos agrotóxicos e não agressivos ao meio ambiente. Nota-se, portanto, que a agricultura orgânica engloba práticas alternativas, excluindo qualquer adição de produtos químicos ou agrotóxicos na produção agrícola (ZEMOLIN, 2012).

No Brasil, a regulação e a normatização dos serviços agropecuários são realizadas pelo Ministério da Agricultura, Pecuária e Abastecimento (Mapa). Além disso, este órgão também é responsável pela gestão das políticas públicas que estimulam a agropecuária, pelo fomento do agronegócio, bem como a cultura e comercialização dos produtos orgânicos no Brasil. Em 23 de dezembro de 2003 foi aprovada a Lei no 10.831, que dispõe sobre agricultura e produtos orgânicos:

Art. $1^{\circ}$ - Considera-se sistema orgânico de produção agropecuária todo aquele em que se adotam técnicas específicas, mediante a otimização do uso dos recursos naturais e socioeconômicos disponíveis e o respeito à integridade cultural das comunidades rurais, tendo por objetivo a sustentabilidade econômica e ecológica, a maximização dos benefícios sociais, a minimização da dependência de energia não renovável, empregando, sempre que possível, métodos culturais, biológicos e mecânicos, em contraposição ao uso de materiais sintéticos, a eliminação do uso de organismos geneticamente modificados e radiações ionizantes, em qualquer fase do processo de produção, processamento, armazenamento, distribuição e comercialização, e a proteção do meio ambiente.

Apenas em 27 de dezembro de 2007, no entanto, com a publicação do Decreto $\mathrm{n}^{\circ}$ 6.323, ocorreu a regulamentação da referida lei (BRASIL, 2007). Assim, para ser considerado um produto orgânico, sua produção deve atender à Lei no 10.831, de 23 de dezem- 
bro de 2003 e ao Decreto no 6.323, de 27 de dezembro de 2007, na íntegra, em todas as fases de seu ciclo produtivo, processamento (quando for o caso) e comercial. Além destes instrumentos legais, o Mapa (2009) acresce que o produto orgânico deve ser produzido em um ambiente de produção orgânica. Ou seja, deve ser cultivado com base nos princípios ecológicos, caracterizados por observar o uso responsável do solo, da água, do ar e dos demais recursos naturais, respeitando as relações sociais e culturais.

Isso posto, para que um produto seja considerado "orgânico", os produtores devem atender aos preceitos desta norma, além da necessidade de obtenção de certificação para tal.

Nesse contexto, os pequenos proprietários rurais, que a exploram com os recursos disponíveis na propriedade rural, especialmente a mão de obra familiar (Lei $n^{\circ} 11.428$, de 22 de dezembro de 2006), veem a agricultura orgânica como um meio de promoção e desenvolvimento econômico e social, bem como uma alternativa de agregação de valor aos produtos que são comercializados em diferentes pontos de venda.

Na cidade de Passo Fundo, no Estado do Rio Grande do Sul, há relatos de iniciativas de comercialização de produtos orgânicos em feiras livres a partir de 1998. Essas iniciativas foram motivadas pela percepção da insustentabilidade dos sistemas convencionais de produção, o aumento do consumo de alimentos ecologicamente corretos, somadas à organização de pequenos agricultores. Atualmente, a Feira de Produtos Orgânicos de Passo Fundo ocorre semanalmente e é promovida pela Cooperativa Mista e de Trabalho Alternativa Ltda. (Coonalter), com apoio da Cáritas Brasileira e do Centro de Tecnologias Alternativas Populares (Cetap).

Com relação aos recursos, a literatura da administração tem contribuído com uma profusão de modelos teóricos que se dedicam a explicar a importância dos recursos no desenvolvimento e consecução das estratégias nas organizações. Entre estes modelos, a teoria selecionada foi a Visão Baseada em Recursos - VBR (Resource-Based View-RBV), a qual fornece um quadro geral de como os recursos são identificados e alavancados por uma empresa para criar vantagem competitiva e sucesso no longo prazo (BARNEY, 1991).

De acordo com Barney e Hesterly (2011), a VBR é um modelo de desempenho com foco nos recursos e nas capacidades controlados por uma empresa como fonte de vantagem competitiva. Nesta teoria, os recursos são definidos como ativos tangíveis e intangíveis que estejam sob controle da empresa e que podem ser utilizados na criação e efetivação de estratégias.

A VBR procura explicar as fontes do sucesso organizacional no longo prazo (BARNEY, 1991; PETERAF, 1993; WERNERFELT, 1984). Sob o pressuposto de que as empresas (organizações) são fundamentalmente heterogêneas em termos de recursos e capacidades, a VBR postula que o sucesso financeiro no longo prazo é fruto da adoção eficiente e efetiva de recursos (PETERAF, 1993). Tais recursos podem ser tangíveis ou intangíveis (BARNEY, 1991) e podem ter diversas fontes de origem (HOOLEY; BRODERICK; MÖLLER, 1998). Para que um recurso contribua para a criação de uma vantagem competitiva sustentável, no entanto, deve ser valioso, raro, inimitável e não substituível (BARNEY, 1991). 
Nas palavras de Barney (1991), as organizações possuem recursos que estão distribuídos através de todos os seus ativos, capacidades, processos organizacionais, atributos, informações, conhecimentos, entre outros itens que ela controla. Além disso, os recursos precisam ser aptos para que a organização aperfeiçoe suas estratégias de modo a otimizar sua eficiência e efetividade. Este referencial teórico, no entanto, foi desenvolvido, principalmente, para indústrias. Um dos desafios apresentados para esta pesquisa foi a utilização destes conceitos para o ambiente de produtores rurais familiares, que possuem níveis organizacionais bastante diferentes das organizações formais de médio e grande porte.

A partir destas ponderações, o objetivo da pesquisa é identificar os recursos tangíveis e intangíveis que se configuram como estratégicos na produção de orgânicos dos produtores da Feira Ecológica de Passo Fundo-RS. Para alcançar o objetivo proposto foi realizada uma pesquisa de caráter exploratório (MALHOTRA, 2001) com abordagem qualitativa, do tipo estudo de caso (GODOY, 1995). A população-alvo foi formada por 34 unidades de produção familiares, oriundas de sete municípios da região de Passo Fundo, que se dedicam à produção e comercialização de produtos orgânicos na Feira Ecológica de Passo Fundo. A seleção dos participantes da pesquisa, num total de seis representantes de unidades familiares, orientou-se pelo critério ponto de saturação, momento em que novos participantes passaram a fornecer informações muito semelhantes às dadas pelos outros participantes. Por se tratar de um grupo homogêneo foram estabelecidos critérios de seleção, tais como serem produtores de alimentos orgânicos, produtores da agricultura familiar, utilizarem mão de obra familiar na produção, serem associados a alguma cooperativa de produtores de orgânicos e que comercializassem seus produtos na Feira Ecológica de Passo Fundo. A VBR ofereceu elementos teóricos que orientaram a elaboração das categorias de análise centradas nos recursos, bem como orientou a elaboração do instrumento de coleta de dados aplicado aos selecionados em setembro de 2016. De posse dos dados coletados, procedeu-se à transcrição e tabulação, que foram organizadas a partir das categorias de análise. A técnica selecionada para as análises foi a de conteúdo (BARDIN, 1997).

Como justificativa, considera-se interessante a oportunidade de investigação de uso dos recursos estratégicos nas atividades de produção rural familiar, especialmente por ser possível verificar as formas como estes atores identificam, mobilizam e utilizam tais recursos que conferem às unidades familiares o sustento nas áreas rurais e, principalmente, como estes produtores encontram nichos de mercado específicos ao comercializarem seus produtos em um mercado permeado pela oferta e concorrência expressiva. Essas questões unem-se à dinâmica da produção e consumo de orgânicos que têm alcançado crescimento consecutivo numa perspectiva global, nacional e local.

\section{AGRICULTURA FAMILIAR E PRODUÇÃO ORGÂNICA}

O universo da agricultura familiar é caracterizado como heterogêneo, seja em termos de disponibilidade de recursos, acesso ao mercado, capacidade de geração de renda e acumulação (BUAINAIN; ROMEIRO; GUANZIROLI, 2003). É uma forma particular de organização de trabalho e de produção, que se reproduz a partir de distintas estratégias produtivas agrícolas e não agrícolas, em consonância com os contextos social e econômico nos quais se insere. Além disso, apresenta formas sociais de trabalho e de produ- 
ção que são condicionadas por fatores internos relacionados ao modo concreto como as famílias gerenciam seus recursos produtivos (terra, capital, tecnologia, entre outros), tomam decisões de investimento e dispêndio, alocam o trabalho de seus integrantes e aderem aos valores culturais do grupo a que pertencem (SCHNEIDER, 2016).

Na América Latina a agricultura familiar tem ampliado o reconhecimento sobre as potencialidades dessa categoria social para o desenvolvimento econômico de vários países da região (CEPAL; FAO; IICA, 2013). Pelo fato de esta atividade utilizar mão de obra familiar local, ela gera ocupação e renda no meio rural, além de responder por, aproximadamente, $77 \%$ do abastecimento alimentar, especialmente em âmbito local e regional (D'ODORICO et al., 2014), o que amplia sua relevância para o desenvolvimento desta parcela da sociedade.

De acordo com o Mapa (BRASIL, 2015a), a agricultura familiar produz $70 \%$ dos alimentos consumidos pelos brasileiros. Dos 5,1 milhões de estabelecimentos agropecuários existentes, mais de 4,3 milhões são caracterizados como estabelecimentos familiares, representando $84,4 \%$ da totalidade dos estabelecimentos agrícolas do país. Além disso, possuem $74 \%$ do total de pessoas que exercem algum tipo de atividade rural, 0 que representa, aproximadamente, 12,3 milhões de trabalhadores (GRANDO, 2011).

Rabaiolli e Miorin (2012) destacam novos valores para as atividades da agricultura familiar, entre eles o incentivo e a valorização do desenvolvimento de práticas reconhecidas como sustentáveis, sejam no âmbito da produção agrícola da terra produtiva, ou de sustentação da família, o que decorre na manutenção da propriedade como fonte de renda. Esta perspectiva corrobora com o entendimento de que as práticas agrícolas se modernizaram em conjunto com os benefícios para a população (PEREIRA et al., 2008). Trouxeram à tona, no entanto, além de questionamentos sociais e econômicos, preocupações quanto aos impactos ambientais destas modernas técnicas, ressaltando o uso indiscriminado de insumos químicos.

Partindo destas ponderações, nota-se que a agricultura orgânica passou a ter destaque, principalmente em razão da crescente demanda da população, preocupada com aspectos ambientais, sociais e de sua própria saúde. Na concepção de Vriesman et al. (2012), os agricultores familiares devem observar a agricultura orgânica como uma oportunidade de desenvolvimento em seus mais diversos âmbitos. Para Moraes e Oliveira (2017), o papel da agricultura orgânica - que compreende desde a produção, o processamento, a distribuição, até o consumo - é o de garantir a sustentabilidade e a saúde dos ecossistemas e organismos que a compõe.

Barbosa e Sousa (2012) pesquisaram as características socioeconômicas dos produtores orgânicos no Brasil e apresentaram algumas variáveis descritivas deste segmento. De acordo com os autores, os produtores orgânicos são, predominantemente, proprietários de suas terras, possuem áreas entre 5 e 50 hectares, acesso limitado à assistência técnica rural (Ater) e reduzida participação em organizações sociais. Dados de 2015 apontaram que, dos 11.084 produtores cadastrados no Cadastro Nacional de Produtores Orgânicos gerenciados pelo Mapa, o Rio Grande do Sul liderava o ranking, com um total de 1.554, seguido de São Paulo, com 1.438, Paraná, com 1.414 e Santa Catarina com 999 produtores (BRASIL, 2015b). 
De acordo com o Instituto de Promoção do Desenvolvimento - IPD (2011), o mercado consumidor reconhece os produtos orgânicos como produtos saudáveis, sem a presença de agrotóxicos, apesar desta isenção nem sempre ser verdadeira, uma vez que a Lei no 10.831, de 23 de dezembro de 2003, não coloca esta prática como obrigatória. Segundo o IPD, o perfil do consumidor de produtos orgânicos é, em sua maioria, formado por pessoas de classe média, com maior nível de escolaridade, geralmente com formação superior, menos sensíveis aos preços atribuídos aos produtos orgânicos, com maior nível de preocupação com a segurança e a qualidade alimentar que lhes é ofertada. De acordo com Dias et al. (2016), os consumidores vêm se tornando mais conscientes quanto ao consumo de alimentos e ao poder de escolha e compra que possuem, ao passo que dispositivos de proteção de seus direitos também evoluem. Também foram criados mecanismos para assegurar a confiança e estabelecer um elo de confiança entre consumidores e produtores/vendedores de produtos orgânicos. Entre esses mecanismos pode-se citar as certificações de produtos orgânicos.

A legislação brasileira de produtos orgânicos, notadamente a Lei no 10.831 , de 23 de dezembro de 2003, e o Decreto no 6.323, de 27 de dezembro de 2007, presume diferentes sistemas de certificação para produtos orgânicos. Os processos de certificação são desenvolvidos com o objetivo de assegurar que tais produtos foram produzidos obedecendo aos requerimentos do tipo de produção em que se encaixam, assim como para que a qualidade e sanidade de determinado alimento também sejam garantidas. Em complemento, para o consumidor, além do certificado de produção, alguns outros aspectos associados são levados em consideração no momento do consumo e podem impactar na percepção de valor e credibilidade dos produtos, como o local de comercialização ou as características do produtor (DIAS et al., 2016).

No Brasil, a certificação, que serve como garantia de conformidade orgânica, apresenta-se sob a forma de selo afixado ou impresso no rótulo ou na embalagem do produto. Cabe ao Mapa acompanhar e fiscalizar os organismos de certificação que, mediante prévia habilitação, fazem a certificação da produção orgânica e sempre devem atualizar as informações dos produtores para alimentar o cadastro nacional de produtores orgânicos. Já no exterior, a International Federation of Organic Agriculture Movements - Ifoam - definida como a federação que congrega os diversos movimentos internacionais relacionados à agricultura orgânica, é o órgão que credencia as certificadoras (ORGANICSNET, 2016).

As feiras livres orgânicas, existentes em vários municípios brasileiros, realizam vendas diretas ao consumidor e assumem grande importância para o fortalecimento da agricultura familiar, pois estes representam mais de $80 \%$ dos produtores orgânicos no Brasil (IBGE, 2006). O Brasil aparece como a quinta maior potência mundial em agricultura orgânica (ORGANICSNET, 2016). Pereira et al. (2008) e Fortes (2009) apontaram que $70 \%$ da produção estava direcionada ao mercado externo. O Brasil exporta sua produção de alimentos orgânicos para mais de 76 países. Os principais produtos exportados são açúcar, mel, oleaginosas, frutas e castanhas (BRASIL, 2015b). Apesar da diversidade de produção em diferentes regiões do Brasil, o setor de produção orgânica ainda é pequeno, enfrentando gargalos nos elos de produção, comercialização e institucionalização (PEREIRA et al., 2008). 
Tendo em vista estes elementos apresentados em torno da agricultura familiar e da produção de orgânicos no Brasil, a próxima discussão centra-se na VBR, que explica os recursos estratégicos necessários à produção que, neste caso, se aplica no contexto de pesquisa mencionado conforme objetivo delimitado.

\section{A VISÃO BASEADA EM RECURSOS (VBR)}

O estudo dos recursos da firma foi inicialmente discutido em 1959, por Edith Penrose, em The Theory of the Growth of the Firm (PENROSE, 2009). Este estudo concluiu que os processos de crescimento de empresas se caracterizam pela existência de oportunidades externas e internas, decorrentes dos seus recursos. Além disso, tem-se a premissa de que as empresas obtêm vantagem aproveitando imperfeições do mercado e que, ao criar produtos únicos, as empresas também desenvolvem capacidades únicas, ou recursos.

Nessa dimensão, Kor e Mahoney (2004) defendem a tese de Penrose, sustentando sua importância para o desenvolvimento da corrente teórica, que mais tarde foi chamada Visão Baseada em Recursos (Resource Based View). Quando a empresa pode ser vista a partir de suas capacidades e recursos, significa que possui características da VBR que, segundo Castro Jr. et al. (2015), ocorre de dentro para fora da organização.

Depois de Penrose (2009), Wernerfelt (1894) tomou como ponto de partida os recursos de uma empresa, em vez de dar enfoque aos produtos, e se propôs a analisar as empresas a partir de novas perspectivas para a estratégia empresarial. Para Wernerfelt (1894) e Barney (1991), recurso em uma empresa é qualquer coisa que possa ser pensada como sendo uma força ou fraqueza. São todos os ativos, capacidades, processos organizacionais, atributos da empresa, informações e conhecimentos que estão sob o seu poder de decisão. Os autores acreditam que é por meio dos recursos que a empresa procura distinguir-se de seus competidores, pois leva em consideração, também, todo o processo de interação entre eles e os efeitos que produzem na organização.

Não basta, no entanto, apenas ter os recursos. É necessário saber suas potencialidades e ter habilidade para utilizá-los de forma que tragam resultados que diferenciem a empresa das concorrentes. Nesta linha, Grant (1991) afirma que não é apenas a estratégia que vai garantir sucesso para uma organização, mas sim a identificação de potencialidades e habilidades da empresa que vão conferir a ela sua permanência no mercado. Estas potencialidades e habilidades são as vantagens competitivas da empresa diante das concorrentes. Da mesma forma, autores como Subramani e Venkataraman (2003) e Hitt, Ireland e Hoskisson (2011) não consideram os fatores tradicionais como fontes de vantagem competitiva eminente, tais como custo da mão de obra, acesso a matérias-primas, recursos financeiros, mercados regulamentados ou protegidos. A explicação para esta perspectiva é que as vantagens competitivas criadas a partir de fatores comuns podem ser suplantadas por concorrentes por meio de estratégias comuns e pelo próprio movimento de acomodação dos recursos nos mercados, à medida que se tornam comuns para todos os competidores.

Nesse contexto, Grant (1991) identifica as vantagens competitivas por meio da manutenção de recursos próprios não imitáveis, pois são estes que garantirão que a empresa permaneça atuando pelo maior tempo possível, sendo mais competitiva no mercado. Begley e Boyd (2003) consideram que as empresas têm de ter recursos e ca- 
pacidades que permitam entender e reagir adequadamente diante da competitividade, esta influenciada por culturas sociais exclusivas e fatores específicos do contexto no qual estão inseridas. Hitt, Ireland e Hoskisson (2011, p. 15), definem recursos como

[...] insumos (inputs) do processo produtivo da empresa, tais como equipamentos importantes, as habilidades de cada funcionário, patentes, finanças e gestores talentosos. Normalmente os recursos de uma empresa são divididos em três categorias: físicas, humanas e capital organizacional. [...] os recursos são de natureza tangível ou intangível.

Na direção dos aspectos relacionados à gestão de recursos, a VBR pressupõe uma forma de obter melhores desempenhos. Algumas pesquisas foram desenvolvidas procurando confirmar esta associação e verificar seu real impacto no desempenho de organizações. Como exemplo, Wernerfelt (1984), Castro Jr. et al. (2015), Barney (1991) e Peteraf (1993), contribuíram para o desenvolvimento e popularização da VBR, aliando-a à competitividade estratégica.

Vale destacar que todas as pesquisas que embasaram o desenvolvimento destes aspectos teóricos foram desenvolvidas tendo como foco grandes empresas, principalmente indústrias, com atuação em mercados amplos que, em muitos casos, transpunham as barreiras geográficas dos países. Além disso, estas empresas, devido aos seus portes, possuem estruturas organizacionais amplas e com funções definidas para os gestores, atuantes em diversos níveis institucionais. Esta, no entanto, não é a realidade encontrada nas pequenas unidades agrícolas familiares alvos desta pesquisa. Assim, para efeitos deste estudo, estas unidades serão consideradas organizações empresariais, que buscam obter melhores resultados financeiros por meio da diferenciação no uso dos recursos disponíveis. Com isso, consegue-se utilizar os conceitos da VBR também para estas pequenas unidades familiares agrícolas.

A seguir serão apresentados os dois grandes tipos de recursos das empresas, que foram classificados em tangíveis e intangíveis. Esta abordagem busca aproximar mais os conceitos da realidade das empresas, ao classificá-los e trazer exemplos práticos e perceptíveis dos diferentes recursos disponíveis.

\section{Recursos Tangíveis}

Conforme Grant (1991), Smith, Collins e Clark (2005) e Winter (2005), os recursos tangíveis podem ser vistos, quantificados e avaliados com clareza. Como exemplos cita-se os recursos humanos, financeiros, equipamentos de produção, fábricas e até mesmo estruturas formais de apresentação de relatórios. Por meio de demonstrações financeiras é possível estipular e demonstrar o valor de recursos tangíveis, no entanto este valor não representa totalmente o valor de todos os ativos, pois ignoram alguns recursos intangíveis (SUBRAMANI; VENKATRAMAN, 2001).

Hitt, Ireland e Hoskisson (2011) apresentam quatro tipos de recursos tangíveis (financeiros, organizacionais, físicos e tecnológicos), conforme o Quadro 1. 
Quadro 1 - Recursos Tangíveis

\begin{tabular}{|l|l|}
\hline \multicolumn{1}{|c|}{$\begin{array}{c}\text { Recursos } \\
\text { Tangíveis }\end{array}$} & \multicolumn{1}{c|}{ Características } \\
\hline Financeiros & $\begin{array}{l}\text { - A capacidade de empréstimo da empresa } \\
\text { - A capacidade da empresa de gerar recursos internamente }\end{array}$ \\
\hline Organizacionais & $\begin{array}{l}\text { - A estrutura formal de apresentação de relatórios da empresa e seus sistemas for- } \\
\text { mais de planejamento, controle e coordenação }\end{array}$ \\
\hline Físicos & $\begin{array}{l}\text { - A sofisticação e localização da fábrica e dos equipamentos de uma empresa } \\
\text { - Acesso a matérias-primas }\end{array}$ \\
\hline Tecnológicos & $\begin{array}{l}\text { - Ações de tecnologia, tais como patentes, marcas registradas, direitos autorais e se- } \\
\text { gredos comerciais }\end{array}$ \\
\hline
\end{tabular}

Fonte: Adaptado de HITT; IRELAND; HOSKISSON, 2011, p. 74.

Entende-se que estes recursos tangíveis também podem ser verificados no contexto das pequenas unidades de produção rural da agricultura familiar, no entanto o conceito de alguns destes recursos deve ser adaptado. Por exemplo, no que diz respeito ao recurso tangível "físico", a "fábrica" pode ser entendida como sendo o próprio espaço agrícola de produção rural, que transforma os insumos (sementes, por exemplo) em produtos (grãos ou frutos, por exemplo) que serão comercializados nas feiras. Este processo de equiparação do meio rural a uma fábrica é compreensível na medida em que os referidos agricultores não são extrativistas. Ao contrário, agem de forma ativa na produção agrícola, visando à obtenção de produtos, de forma cíclica (safras), para a comercialização nas feiras específicas. Nesse mesmo sentido, os "equipamentos", por exemplo, podem ser entendidos como os implementos agrícolas, mesmo que rudimentares, utilizados no processo produtivo e nos tratos culturais, que favorecem a obtenção dos produtos a serem comercializados. Este mesmo raciocínio aplica-se aos recursos tecnológicos. Dado o tipo de atividade das pequenas unidades de produção da agricultura familiar, as ações de tecnologia, além da tecnologia disponível e acessada pelos produtores, pode-se encontrar também aquelas geradas por eles, que possuem direitos autorais e segredos comerciais. Ou seja, a forma como cada organização vai atuar no âmbito da produção agrícola e da sua comercialização torna estes recursos diferenciadores para a obtenção de resultados que não são comuns aos demais competidores.

\section{Recursos Intangíveis}

Os recursos intangíveis não permitem ser diretamente observados e podem ser difíceis de serem analisados por concorrentes. Como exemplos cita-se o conhecimento, a cultura organizacional, a reputação da empresa, as habilidades tecnológicas ou gerenciais que não estão registradas e os relacionamentos entre clientes, fornecedores, colaboradores, entre outros (GRANT, 1991).

Ainda, para autores como Smith, Collins e Clark (2005) e Winter (2005), os recursos intangíveis abrangem os ativos que comumente estão "profundamente enraizados no histórico da empresa e foram acumulados com o tempo". Além dos exemplos citados por Grant (1991), os autores acreditam que, entre os recursos intangíveis, esteja também a maneira peculiar de como empregados trabalham juntos, a habilidade de 
inovação, as capacidades científicas da empresa, a sua reputação devido aos seus bens e serviços e como ela interage com as pessoas, sejam elas clientes, funcionários ou fornecedores.

De acordo com Song et al. (2005) e Schroeder, Bates e Junttila (2002), os ativos do processo produtivo são tangíveis, mas muitos dos processos que utilizam esses ativos são intangíveis. Assim, o conhecimento adquirido e possíveis processos ímpares associados aos recursos tangíveis, como equipamentos de manufatura, podem ter características intangíveis específicas, por exemplo, processos de controle de qualidade, processos de manufatura exclusivos e tecnologia, desenvolvidos no decorrer do tempo que criam vantagem competitiva.

Ireland, Hitt e Vaidyanath (2002) explicam ainda que outro benefício dos recursos intangíveis é que seu uso pode ser alavancado, ao contrário dos recursos tangíveis. Os autores utilizam como exemplo o compartilhamento de conhecimentos entre funcionários. Este processo não diminui o valor do conhecimento. Desta forma, Hitt, Ireland e Hoskisson (2011) apresentam três tipos de recursos intangíveis, humanos, de inovações e os que são ligados à reputação da empresa (Quadro 2).

Quadro 2-Recursos Intangíveis

\begin{tabular}{|c|c|}
\hline $\begin{array}{l}\text { Recursos } \\
\text { Intangíveis }\end{array}$ & Características \\
\hline Humanos & $\begin{array}{l}\text { - Conhecimento } \\
\text { - Confiança } \\
\text { - Capacitações gerenciais } \\
\text { - Rotinas organizacionais }\end{array}$ \\
\hline De Inovações & $\begin{array}{l}\text { - Ideias } \\
\text { - Capacitações científicas } \\
\text { - Capacitações de inovar }\end{array}$ \\
\hline $\begin{array}{l}\text { Relacionados à } \\
\text { Reputação }\end{array}$ & $\begin{array}{l}\text { - Reputação para com os clientes } \\
\text { - Marca } \\
\text { - Percepções de qualidade, durabilidade e confiabilidade no produto } \\
\text { - Reputação para os fornecedores } \\
\text { - Para interações e relações eficientes, eficazes, de suporte e mutuamente benéficas }\end{array}$ \\
\hline
\end{tabular}

Fonte: Adaptado de HITT; IRELAND; HOSKISSON, 2011, p. 74.

Partindo da premissa de que os recursos podem configurar-se tanto tangíveis como intangíveis, a próxima seção apresenta a discussão dos resultados a partir dos dados coletados nas entrevistas realizadas com os produtores de produtos orgânicos.

\section{APRESENTAÇÃO E DISCUSSÃO DOS RESULTADOS}

No início da década de 80 do século 20, um grupo de pessoas, percebendo a insustentabilidade dos sistemas convencionais de produção e consumo, começou a repensar e se reorganizar quanto à forma de produção agrícola e o comércio da cidade. $O$ grupo de agricultores sempre idealizou realizar uma feira ecológica na cidade de Passo Fundo, até que em 1997 a Cáritas Diocesana e a Cooperativa Mista e de Trabalho Alternativa Ltda. (Coonalter), assessoradas pelo Centro de Tecnologias Alternativas Populares (Cetap), organizaram um encontro para discutir a comercialização dos produtos. Deste 
grupo de trabalho, formado por representantes das regiões e de entidades presentes, nasceu o Fórum de Agroecologia, com o apoio conjunto da Coonalter, Cetap, Cáritas, Pastoral Rural e Grupo Ecológico Sentinela dos Pampas (Gesp).

Além dos princípios agroecológicos, os ideais do cooperativismo e da economia popular solidária fazem parte do dia a dia dos agricultores. A responsabilidade técnica pelos produtos comercializados na feira é do Cetap, com sede na cidade de Passo Fundo. A certificação da produção ecológica é de forma participativa, feita pelos próprios produtores, consumidores e técnicos. Cabe mencionar que, se tratando da certificação dos produtos orgânicos, esta é realizada de maneira participativa, sob o apoio e orientação da Coonalter, da Cáritas e do Cetap, os quais se vinculam à Rede Ecovida de Agroecologia, fundada em 1998, funcionando de maneira descentralizada, que se baseia na formação de núcleos regionais, adotando a "certificação participativa". Seu trabalho desenvolve-se na dimensão pedagógica, em que agricultores, técnicos e consumidores, alcançam credibilidade e seriedade em todas as etapas do processo de produção. Esse modelo de certificação de produção orgânica contrapõe-se ao modelo mais comum, que é realizado por meio de auditoria por inspeção externa.

Na sequência, a Tabela 1 apresenta o panorama das famílias que comercializam seus produtos na Feira Ecológica no município de Passo Fundo.

Tabela 1 - Composição de Feirantes da Feira Ecológica de Passo Fundo

\begin{tabular}{|l|l|c|c|}
\hline Grupos & Município & No de famílias & $\begin{array}{c}\text { № de trabalha- } \\
\text { dores familiares }\end{array}$ \\
\hline Santo Antônio & Santo Antônio do Palma & 8 & 35 \\
\hline Cristo Rei & Santo Antônio do Palma e Vila Maria & 10 & 23 \\
\hline São João da Urtiga & São João da Urtiga & 5 & 15 \\
\hline Ecoterra & Três Arroios & 6 & 20 \\
\hline Sabores da Terra & São Domingos do Sul & 1 & 6 \\
\hline Sagra Italiana & São Domingos do Sul & 4 & 25 \\
\hline TOTAL & 7 & 34 & 124 \\
\hline
\end{tabular}

Fonte: Dados do estudo (2016).

Os dados expressos na Tabela 1 apresentam a repercussão da produção dos agricultores familiares que, somente neste ponto de venda, Feira Ecológica de Passo Fundo, congrega todos os sábados pela manhã um total de 5 municípios, 34 famílias produtoras que somam 124 trabalhadores nestas unidades de produção familiar.

\section{Caracterização dos Entrevistados e das Propriedades Rurais}

Com o intuito de preservar a identificação dos participantes da pesquisa, foi atribuída identificação numérica individual $(1,2,3,4,5$ e 6), com o objetivo de diferenciar as respostas no momento da análise. A etapa a seguir dedica-se à caracterização das unidades de produção, indicando a localização, ano de início da produção orgânica, área destinada e a participação da produção de orgânicos comparada à área total (Tabela 2). 
Tabela 2 - Especificidades das Propriedades Estudadas

\begin{tabular}{|l|l|l|l|l|l|}
\hline $\begin{array}{l}\text { Respon- } \\
\text {-dentes }\end{array}$ & Município & $\begin{array}{l}\text { Início } \\
\text { da produção } \\
\text { orgânica }\end{array}$ & $\begin{array}{l}\text { Área total } \\
\text { (em ha) }\end{array}$ & $\begin{array}{l}\text { Área de produ- } \\
\text { ção } \\
\text { orgânica } \\
\text { (em ha) }\end{array}$ & $\begin{array}{l}\text { Área de produção } \\
\text { orgânica compara- } \\
\text { da à área total } \\
\text { (em \%) }\end{array}$ \\
\hline 1 & São Domingos do Sul & 1996 & 23 & 8 & 34,8 \\
\hline 2 & São Domingos do Sul & 2002 & 11 & 3 & 27,3 \\
\hline 3 & Santo Antônio do Palma & 1996 & 25 & 12 & 48 \\
\hline 4 & Santo Antônio do Palma & 2003 & 6,5 & 3,5 & 53,85 \\
\hline 5 & São João da Urtiga & 2007 & 19 & 3 & 15,79 \\
\hline 6 & Três Arroios & 2013 & 14 & 2 & 14,29 \\
\hline
\end{tabular}

Fonte: Pesquisa de Campo (2016).

Em todas as propriedades a iniciativa para o desenvolvimento da produção de orgânicos foi coletiva. Seu desenvolvimento ancorou-se na organização de grupos de produtores locais e regionais, cultivo de produtos saudáveis e busca por uma fonte de renda extra que posteriormente, em alguns casos, consolidou-se como a principal renda da unidade familiar. Informação importante identificada entre os entrevistados relaciona-se ao período de transição da terra, ou seja, a área antes utilizada para agricultura convencional pode levar até quatro anos para tornar-se apta para a produção de alimentos orgânicos, o que gera a aplicação de conhecimento específico do manejo de área a ser cultivada com a produção de orgânicos, bem como as decisões e recursos, tanto tangíveis quanto intangíveis, nesta etapa de gestão.

Em se tratando da percepção dos produtores com relação à exigência dos consumidores, o Quadro 3 traz um resumo da etapa qualitativa que buscou contemplar estes elementos, entendidos como importantes para melhor conhecimento do setor pesquisado.

Quadro 3 - Percepção dos produtores quanto à exigência do consumidor dos produtos da Feira

\begin{tabular}{|l|l|}
\hline Respondentes & Percepção \\
\hline 1 & $\begin{array}{l}\text { Quem é mais consciente e já entende o que é produto orgânico não se importa e não } \\
\text { reclama, tanto do produto, quanto em termos de aparência. Mas quem não entende a } \\
\text { proposta da feira e não conhece, acha que é feira comum e reclama do preço. Muitas } \\
\text { vezes, isso é atribuído à consciência de cultura que às vezes não conhece o produto } \\
\text { também. }\end{array}$ \\
\hline 2 & $\begin{array}{l}\text { Buscam por produtos prontos, ou seja, mandioca descascada, abóbora descascada. } \\
\text { Gostam de escolher bastante a partir da aparência dos produtos. }\end{array}$ \\
\hline 3 & $\begin{array}{l}\text { Exigem que sejam produtos bons, de boa aparência e higienizados. } \\
\text { O público sempre pergunta se tem agrotóxico ou veneno, né? Eu acredito que eles } \\
\text { que não utilizamos agrotóxicos na produção dos produtos. No final, eles acabam sem- } \\
\text { pre comprando nossos produtos e voltam mais vezes. } \\
\text { Por exemplo, eu moro em uma baixada e os outros granjeiros passam veneno lá no alto } \\
\text { e desce, e aí não temos como garantir que é 100\% orgânico. Isso é um problema que } \\
\text { não temos como evitar. }\end{array}$ \\
\hline 5 & $\begin{array}{l}\text { Apresentável, confiança que o produto é bom, através de elogios de terceiros. } \\
\text { Não precisa ser perfeito, essa é a diferença do orgânico para o convencional. O conven- } \\
\text { cional tem que ser perfeito, ou é descartado. As pessoas não se importam se a fruta } \\
\text { não está perfeita. }\end{array}$ \\
\hline
\end{tabular}




\begin{tabular}{|l|l|}
\hline 6 & $\begin{array}{l}\text { Um exemplo que dá para citar são os nossos tomates. Nessa época, na nossa região, } \\
\text { todo mundo sabe que não produz tomate por causa do frio, né? A gente está conse- } \\
\text { guindo tomate porque é associado à Ecoterra, que tem o circuito de produtos orgâni- } \\
\text { cos. Daí, o que a gente tem excesso aqui, eles mandam pra lá, e que eles têm de sobra } \\
\text { lá. Nesse caso, os clientes que sabem o que é um produto orgânico sempre entendem } \\
\text { que, se não tiver uma aparência bonita, é o resultado da época de produção. }\end{array}$ \\
\hline
\end{tabular}

Fonte: Dados do estudo (2016).

Ampliando a caracterização dos produtores que participaram da entrevista, também foi questionada a composição da renda familiar. Nessa dimensão, pode-se perceber que a renda da família rural é composta, praticamente, pelo rendimento da atividade de produção orgânica, seguida do recebimento de aposentadorias de alguns dos integrantes das famílias. Foi possível, portanto, identificar que a produção orgânica possui relevância para as famílias, especialmente pela participação na formação da renda, bem como os aspectos relacionados à interação social que integram o cotidiano destas famílias ao se observar a aquisição, troca de conhecimentos e o contato com outras pessoas, antes desconhecidas.

Por outro lado, também foi possível identificar aspectos negativos, os quais referem-se ao local em que a feira acontece em Passo Fundo, que apresenta falta de infraestrutura, especialmente no que se refere à falta de estacionamento e disponibilidade de banheiros para uso dos feirantes. Outro elemento importante coletado nas entrevistas relaciona-se ao desconhecimento, por parte do consumidor, com relação às especificidades dos produtos orgânicos que, geralmente, confundem ou associam com o convencional, o que gera certa desconfiança de alguns consumidores com relação aos produtos.

Apresentadas estas considerações acerca da resumida caracterização dos pesquisados, a próxima discussão centra-se nos recursos estratégicos, como elementos importantes que viabilizam a produção de orgânicos dos produtores que comercializam seus produtos na Feira Ecológica de Passo Fundo.

\section{Recursos Estratégicos na Produção de Orgânicos}

Em se tratando de recursos, Barney (1991, p. 101) define-os com sendo "todos os ativos, capacidades, processos organizacionais, atributos, informação, entre outros, controlados pela empresa, que permitam a ela conceber e implementar estratégias que melhorem a sua eficiência e eficácia". Conforme apresentado, quanto à sua natureza, os recursos podem ser classificados e avaliados como tangíveis ou intangíveis (HITT; IRELAND; HOSKISSON, 2011; GRANT, 1991; BARNEY, 1991; BARNEY; HESTERLY, 2011).

Nessa perspectiva, o Quadro 4 apresenta a sistematização dos dados relacionados aos recursos tangíveis que produtores de orgânicos mobilizam e utilizam em suas práticas de produção. 
Quadro 4-Recursos tangíveis identificados na produção de orgânicos

\begin{tabular}{|c|c|c|c|c|}
\hline $\begin{array}{l}R \text { e } s- \\
p \text { o } n- \\
\text { dentes }\end{array}$ & Financeiros & Organizacionais & Físicos & Tecnológicos \\
\hline 1 & $\begin{array}{l}\text { - Capital próprio } \\
\text { - Aposentadorias }\end{array}$ & $\begin{array}{l}\text { - Coordenação e geren- } \\
\text { ciamento } \\
\text { - Controle financeiro }\end{array}$ & $\begin{array}{l}\text { - Máquinas } \\
\text { - Equipamentos } \\
\text { - Estradas de acesso } \\
\text { - Linhas de transmissão de ener- } \\
\text { gia elétrica } \\
\text { - Fonte de água } \\
\text { - Moradia } \\
\text { - Galpões } \\
\text { - Estufas }\end{array}$ & $\begin{array}{l}\text { - Computador } \\
\text { - Internet } \\
\text { - Telefone }\end{array}$ \\
\hline 2 & $\begin{array}{l}\text { - Capital próprio } \\
\text { - Capital de ter- } \\
\text { ceiros }\end{array}$ & $\begin{array}{l}\text { - Cursos de gestão } \\
\text { - Habilidade em organi- } \\
\text { zar atividades de plantio } \\
\text { e colheita }\end{array}$ & $\begin{array}{l}\text { - Máquinas } \\
\text { - Equipamentos } \\
\text { - Galpões } \\
\text { - Estrada de acesso } \\
\text { - Linhas de transmissão de ener- } \\
\text { gia elétrica } \\
\text { - Fonte de água } \\
\text { - Moradia }\end{array}$ & $\begin{array}{l}\text { - Computador } \\
\text { - Internet } \\
\text { - Telefone }\end{array}$ \\
\hline 3 & $\begin{array}{l}\text { - Capital próprio } \\
\text { - Capital de ter- } \\
\text { ceiros } \\
\text { - Aposentadorias }\end{array}$ & $\begin{array}{l}\text { - Planejamento da pro- } \\
\text { dução } \\
\text { - Controle e gerencia- } \\
\text { mento de receitas e des- } \\
\text { pesas }\end{array}$ & $\begin{array}{l}\text { - Máquinas } \\
\text { - Equipamentos } \\
\text { - Veículos para transporte da } \\
\text { produção } \\
\text { - Galpões } \\
\text { - Estrada de acesso } \\
\text { - Linhas de transmissão de ener- } \\
\text { gia elétrica } \\
\text { - Fonte de água } \\
\text { - Moradia }\end{array}$ & $\begin{array}{l}\text { - Computador } \\
\text { - Internet } \\
\text { - Telefone }\end{array}$ \\
\hline 4 & $\begin{array}{l}\text { - Capital próprio } \\
\text { - Capital de ter- } \\
\text { ceiros }\end{array}$ & $\begin{array}{l}\text { - Controle de receitas } \\
\text { e despesas- Sistema de } \\
\text { fixação de preço de ven- } \\
\text { da- Produção orientada } \\
\text { ao mercado }\end{array}$ & $\begin{array}{l}\text { - Máquinas } \\
\text { - Equipamentos } \\
\text { - Galpões } \\
\text { - Estrada de acesso } \\
\text { - Linhas de transmissão de ener- } \\
\text { gia elétrica } \\
\text { - Fonte de água- Rede de comu- } \\
\text { nicação } \\
\text { - Moradia }\end{array}$ & - Telefone \\
\hline 5 & $\begin{array}{l}\text { - Capital próprio } \\
\text { - Capital de ter- } \\
\text { ceiros } \\
\text { - Aposentadorias } \\
\text { - Salários de em- } \\
\text { prego urbano }\end{array}$ & $\begin{array}{l}\text { - Gestão da produção- } \\
\text { Sistema de fixação de } \\
\text { preço de vendaProspec- } \\
\text { ção de novos mercados }\end{array}$ & $\begin{array}{l}\text { - Máquinas } \\
\text { - Equipamentos } \\
\text { - Estrada de acesso } \\
\text { - Linhas de transmissão de ener- } \\
\text { gia elétrica } \\
\text { - Fonte de água- Moradia } \\
\text { - Galpões } \\
\text { - Estufas }\end{array}$ & $\begin{array}{l}\text { - Computador } \\
\text { - Internet } \\
\text { - Telefone } \\
\text { - Sistema de irri- } \\
\text { gação }\end{array}$ \\
\hline 6 & $\begin{array}{l}\text { - Capital próprio } \\
\text { - Aposentadorias }\end{array}$ & $\begin{array}{l}\text { - Controle de receitas e } \\
\text { despesas- Sistema de fi- } \\
\text { xação de preço de venda }\end{array}$ & $\begin{array}{l}\text { - Máquinas } \\
\text { - Equipamentos } \\
\text { - Estrada de acesso } \\
\text { - Linhas de transmissão de ener- } \\
\text { gia elétrica } \\
\text { - Fonte de água- Moradia } \\
\text { - Galpões } \\
\text { - Estufas }\end{array}$ & $\begin{array}{l}\text { - Computador } \\
\text { - Internet } \\
\text { - Telefone }\end{array}$ \\
\hline
\end{tabular}

Fonte: Dados do estudo (2016). 
De acordo com os dados coletados com os entrevistados e a literatura utilizada, foi possível identificar nas falas dos pesquisados os recursos tangíveis utilizados na produção orgânica. Esse é um ponto relevante a destacar, especialmente pelas características específicas de atividades de produção primária que, em determinados aspectos, poderia configurar-se como limitador neste tipo de contexto e unidade de análise. Nesse contexto, parecem fazer sentido as contribuições que a literatura sobre os recursos estratégicos oferece, especialmente por avançar na explicação deste tipo de fenômeno que vai além do porte e estrutura organizacional, constituindo-se como um ferramental que auxilia nas decisões de produção, comercialização e investimentos que culminam para o sucesso das atividades no meio rural.

A próxima etapa centra-se na identificação dos recursos intangíveis utilizados pelos produtores de orgânicos pesquisados (Quadro 5).

Quadro 5 - Recursos intangíveis identificados na produção de orgânicos

\begin{tabular}{|c|c|c|c|}
\hline $\begin{array}{l}\text { R e } s- \\
p \text { o } n- \\
\text { dentes }\end{array}$ & Humanos & De Inovação & Relacionados à Reputação \\
\hline 1 & $\begin{array}{l}\text { - Conhecimento téc- } \\
\text { nico de produção } \\
\text { - Proatividade } \\
\text { - Habilidades de ge- } \\
\text { renciamento }\end{array}$ & $\begin{array}{l}\text { - Adoção de novas técni- } \\
\text { cas de produção } \\
\text { - Ampliação da oferta e } \\
\text { variedade de produtos } \\
\text { comercializados }\end{array}$ & $\begin{array}{l}\text { - Conceito e imagem de saúde } \\
\text { - Qualidade dos produtos } \\
\text { - Confiança dos consumidores } \\
\text { - Aceitação da comunidade }\end{array}$ \\
\hline 2 & $\begin{array}{l}\text { - Realização de cur- } \\
\text { sos de gestão } \\
\text { - Convívio com a fa- } \\
\text { mília } \\
\text { - Habilidade de or- } \\
\text { ganizar atividades de } \\
\text { plantio e colheita }\end{array}$ & $\begin{array}{l}\text { - Adaptação e modifica- } \\
\text { ção de técnicas de produ- } \\
\text { ção } \\
\text { - Pesquisa de novas varie- } \\
\text { dades de sementes }\end{array}$ & $\begin{array}{l}\text { - Esforço em transmitir imagem positiva aos } \\
\text { consumidores } \\
\text { - Qualidade dos produtos afetada pelo clima } \\
\text { - Satisfação dos consumidores } \\
\text { - Confiança dos consumidores }\end{array}$ \\
\hline 3 & $\begin{array}{l}\text { - Convívio com pes- } \\
\text { soas }\end{array}$ & $\begin{array}{l}\text { - Pesquisa de inovações } \\
\text { no setor }\end{array}$ & $\begin{array}{l}\text { - Conceito e imagem de saúde } \\
\text { - Confiança dos consumidores } \\
\text { - Fidelização dos consumidores } \\
\text { - Qualidade dos produtos }\end{array}$ \\
\hline 4 & $\begin{array}{l}\text { - Vontade de apren- } \\
\text { der } \\
\text { - Conhecimentos } \\
\text { técnicos adaptados } \\
\text { através de experiên- } \\
\text { cia de produção ru- } \\
\text { ral }\end{array}$ & $\begin{array}{l}\text { - Produção orientada ao } \\
\text { mercado } \\
\text { - Oferta de novos produ- } \\
\text { tos } \\
\text { - Preocupação constante } \\
\text { em inovar na oferta de } \\
\text { produtos }\end{array}$ & $\begin{array}{l}\text { - Produtores orgânicos } \\
\text { - Imagem de saúde repassada ao cliente- Quali- } \\
\text { dade dos produtos } \\
\text { - Fidelização dos consumidores } \\
\text { - Confiança dos consumidores } \\
\text { - Consumidor valoriza a diversidade e novos } \\
\text { produtos }\end{array}$ \\
\hline 5 & $\begin{array}{l}\text { - Conhecimento da } \\
\text { produção de orgâni- } \\
\text { cos } \\
\text { - Convívio com as } \\
\text { pessoas } \\
\text { - Troca de conheci- } \\
\text { mentos }\end{array}$ & $\begin{array}{l}\text { - Conhecimento de novas } \\
\text { técnicas de produção } \\
\text { - Orientação ao consu- } \\
\text { midor (mercado) sobre } \\
\text { técnicas de produção de } \\
\text { novos produtos }\end{array}$ & $\begin{array}{l}\text { - Percepção de organização do produtor } \\
\text { - Percepção dos produtores de sustentabilidade } \\
\text { ambiental } \\
\text { - Qualidade dos produtos } \\
\text { - Fidelização dos consumidores } \\
\text { - Confiança dos consumidores } \\
\text { - Consumidores retornam semanalmente } \\
\text { - Produção orgânica chamada de bonita }\end{array}$ \\
\hline
\end{tabular}




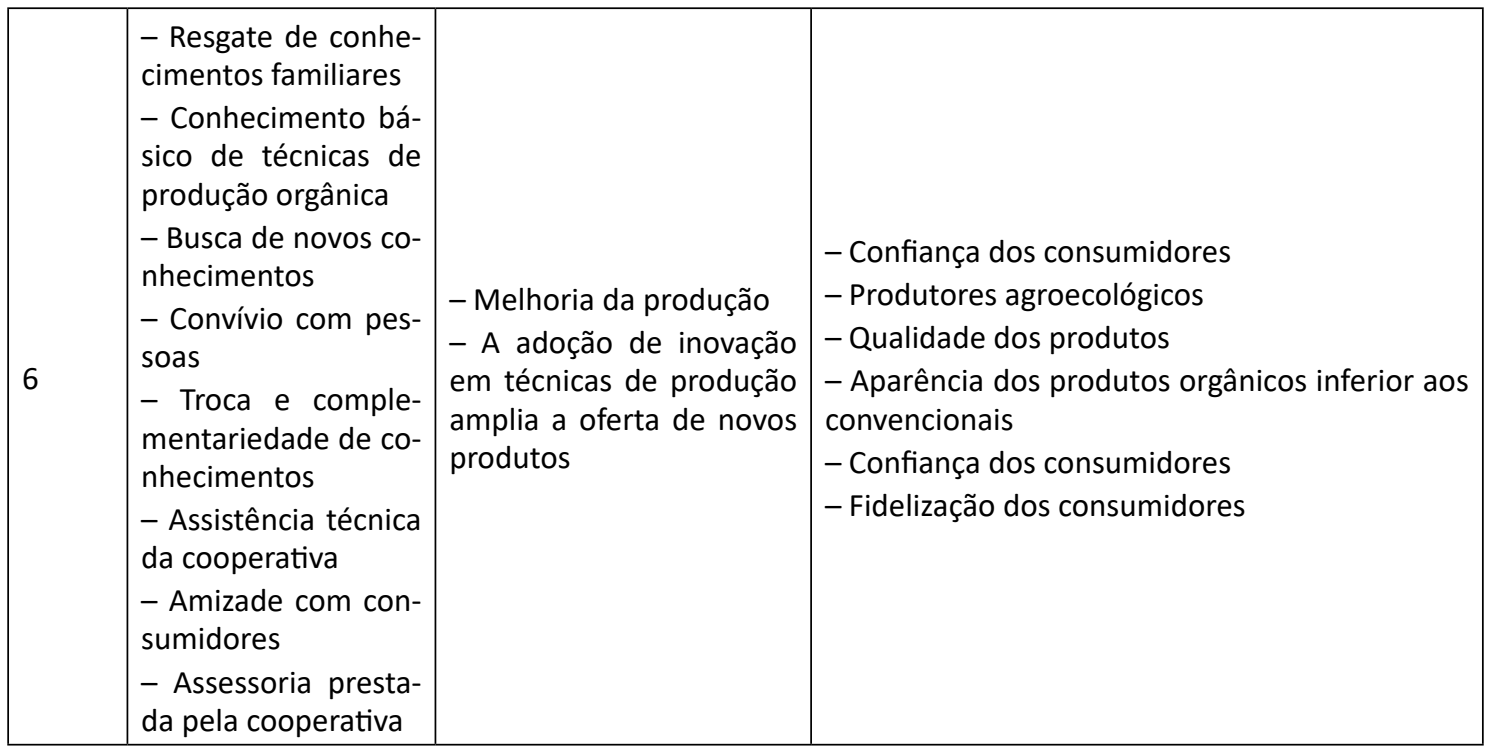

Fonte: Dados do estudo (2016).

Observado os recursos intangíveis, segundo a percepção dos entrevistados, destaque especial pode ser inferido aos "humanos", especialmente por estes incluírem a mão de obra familiar como recurso relevante na produção orgânica, o conhecimento implícito dos membros da família rural, a confiança, capacitação gerencial e domínio das técnicas de produção orgânica. Quanto aos recursos de "inovação", pode-se observar uma preocupação constante com a identificação de novas técnicas de produção e variedades que o ambiente externo oferece, o que se alia à preocupação de satisfação crescente do público consumidor de orgânicos, caracterizado, pelos próprios produtores, como "cada vez mais exigente". Com relação à "reputação", pode-se observar crescente preocupação dos entrevistados com aspectos relacionados à qualidade dos produtos comercializados na feira, a durabilidade e a confiabilidade dos produtos, além da manutenção de relações sociais entre produtor e consumidor. Nessa dimensão de análise, pode-se observar o desafio de tais produtores que exploram os recursos intangíveis em suas práticas de produção, especialmente por serem difíceis de imitar ou copiar.

Apresentados os recursos tangíveis e intangíveis identificados pelos produtores de orgânicos pesquisados, o estudo também procurou fazer um contraponto, buscando compreender as facilidades e dificuldades de alocação de tais recursos. Os dados coletados forma resumidos e dispostos no Quadro 6. 
Quadro 6 - Facilidade e dificuldades na alocação de recursos na produção de orgânicos

\begin{tabular}{|c|c|c|c|c|}
\hline \multirow{2}{*}{$\begin{array}{l}\text { R e s - } \\
p \text { o } n- \\
\text { dentes }\end{array}$} & \multicolumn{2}{|l|}{ Recursos Tangíveis } & \multicolumn{2}{|l|}{ Recursos Intangíveis } \\
\hline & Facilidades & Dificuldades & Facilidades & Dificuldades \\
\hline 1 & $\begin{array}{l}\text { - Capital próprio } \\
\text { - Aposentadorias } \\
\text { - Capital de terceiros } \\
\text { - Não utiliza agrotóxico } \\
\text { - Localização } \\
\text { - Destino final dos resí- } \\
\text { duos de produção } \\
\text { - Controle financeiro } \\
\text { - Aumento da renda }\end{array}$ & $\begin{array}{l}\text { - Falta de uma linha de } \\
\text { crédito específica para } \\
\text { a produção orgânica } \\
\text { - Escassez e custo da } \\
\text { mão de obra } \\
\text { - Custos elevados de } \\
\text { produção } \\
\text { - Mão de obra escassa } \\
\text { e de custo elevado } \\
\text { - Divulgação }\end{array}$ & $\begin{array}{l}\text { - Incentivos de grupos } \\
\text { de produtores } \\
\text { - Apoio técnico } \\
\text { - Capacitações } \\
\text { - Conhecimentos res- } \\
\text { gatados de outras gera- } \\
\text { ções } \\
\text { - Qualidade de vida } \\
\text { - Proatividade } \\
\text { - Membros da família } \\
\text { com capacidades bási- } \\
\text { cas de gerenciamento }\end{array}$ & $\begin{array}{l}\text { - Consumidores } \\
\text { que não sabem di- } \\
\text { ferenciar orgânico } \\
\text { e convencional } \\
\text { - Qualidade nem } \\
\text { sempre percebida } \\
\text { - Qualidade dos } \\
\text { produtos }\end{array}$ \\
\hline 2 & $\begin{array}{l}\text { - Capital próprio } \\
\text { - Acesso a financiamen- } \\
\text { tos } \\
\text { - Aumento da renda } \\
\text { - Preservação do meio } \\
\text { ambiente } \\
\text { - Cursos de gestão } \\
\text { - Convívio com a família } \\
\text { - Habilidade em organi- } \\
\text { zar atividades de plantio } \\
\text { e colheita. }\end{array}$ & $\begin{array}{l}\text { - Escassez de mão de } \\
\text { obra } \\
\text { - Características do solo } \\
\text { limitam a ampliação do } \\
\text { portfolio de produção } \\
\text { - Geadas } \\
\text { - Localização da feira }\end{array}$ & $\begin{array}{l}\text { - Incentivo de grupos } \\
\text { de produtores } \\
\text { - Apoio técnico } \\
\text { - Conhecimento } \\
\text { - Técnicas de produção } \\
\text { - Convivência }\end{array}$ & $\begin{array}{l}\text { Qualidade nem } \\
\text { sempre condiz com } \\
\text { o que é oferecido } \\
\text { em função do clima }\end{array}$ \\
\hline 3 & $\begin{array}{l}\text { - Capital próprio } \\
\text { - Acesso a financiamen- } \\
\text { tos } \\
\text { - Aposentadorias- Be- } \\
\text { nefícios financeiros. }\end{array}$ & $\begin{array}{l}\text { Estoque de produtos } \\
\text { não comercializados na } \\
\text { feira }\end{array}$ & $\begin{array}{l}\text { - Incentivos de grupos } \\
\text { de produtores } \\
\text { - Apoio técnico- Valo- } \\
\text { rização dos produtos- } \\
\text { Aquisição de conheci- } \\
\text { mentos- Técnicas de } \\
\text { produção }\end{array}$ & Não identificou \\
\hline 4 & $\begin{array}{l}\text { - Capital próprio- Bene- } \\
\text { fícios financeiros- Co- } \\
\text { nhecimento da maneira } \\
\text { de convívio com as pes- } \\
\text { soas }\end{array}$ & Não identificou & $\begin{array}{l}\text { - Apoio técnico } \\
\text { - Reconhecimento } \\
\text { - Técnicas de produção } \\
\text { - Conhecimentos res- } \\
\text { gatados de outras gera- } \\
\text { ções }\end{array}$ & $\begin{array}{l}\text { Entendimento de } \\
\text { como realizar cor- } \\
\text { retamente as ati- } \\
\text { vidades ligadas à } \\
\text { produção orgânica }\end{array}$ \\
\hline 5 & $\begin{array}{l}\text { - Acesso a financiamen- } \\
\text { tos } \\
\text { - Capital próprio- Apo- } \\
\text { sentadorias- Salário } \\
\text { - Consumo de produtos } \\
\text { saudáveis pela família- } \\
\text { Benefícios financeiros }\end{array}$ & $\begin{array}{l}\text { Carência de mão de } \\
\text { obra }\end{array}$ & $\begin{array}{l}\text { - Incentivos de grupos } \\
\text { de produtores } \\
\text { - Apoio técnico }\end{array}$ & $\begin{array}{l}\text { Morosidade no } \\
\text { apoio técnico }\end{array}$ \\
\hline 6 & $\begin{array}{l}\text { - Capital próprio } \\
\text { - Aposentadorias } \\
\text { - Aumento da renda }\end{array}$ & Não identificou & $\begin{array}{l}\text { - Aquisição de novos } \\
\text { conhecimentos } \\
\text { - Convivência e intera- } \\
\text { ção com pessoas } \\
\text { - Conhecimentos res- } \\
\text { gatados de outras gera- } \\
\text { ções } \\
\text { - Apoio técnico e su- } \\
\text { porte } \\
\text { Amizade com clientes }\end{array}$ & $\begin{array}{l}\text { - Convencer fami- } \\
\text { liares de que a pro- } \\
\text { dução seria viável } \\
\text { financeiramente } \\
\text { - Desconfiança dos } \\
\text { consumidores } \\
\text { - Aparência dos } \\
\text { produtos orgânicos } \\
\text { inferior aos con- } \\
\text { vencionais }\end{array}$ \\
\hline
\end{tabular}

Fonte: Dados do estudo (2016). 
Analisando o Quadro 6, verifica-se que os produtores orgânicos detêm conhecimento das técnicas de produção, apresentando potencial interessante no crescimento e desenvolvimento da atividade de produção. Esse entendimento pode estar relacionado ao tempo de atuação no setor (Tabela 2), bem como o know-how de produção de alimentos que se alia à organização em torno de um sistema cooperativo, sob a certificação de instituição que oferece respaldo às famílias entrevistadas. Não somente isso, parece fazer sentido analisar os recursos tangíveis e intangíveis neste tipo de produção, caracterizada pela crescente demanda, adoção de inovações, prospecção de novos mercados e, especialmente, contribuir para geração de renda de pequenos produtores familiares

\section{DISCUSSÃO DOS RESULTADOS}

A literatura da VBR em seu contexto de aplicação empírica, indubitavelmente é investigada e utilizada, em grande medida, no contexto estratégico empresarial. Dessa forma, pode-se perceber que a teoria também se mostrou válida ao oferecer suporte de investigação dos recursos tangíveis e intangíveis na produção de orgânicos, ao se fazer os devidos ajustes de aplicabilidade para o contexto das pequenas organizações familiares de produção agrícola, conforme apresentado na abordagem teórica. Tratando-se de recursos tangíveis, pode-se identificar o financeiro (com diferentes aportes e fontes de capital), o físico (relativo à infraestrutura disponível nas propriedades familiares) e tecnológico (identificado pelo uso de meios de comunicação que incluem telefone e Internet). Quanto aos organizacionais, foram mencionados o planejamento da produção, o controle e gerenciamento de receitas e despesas, sistema de fixação de preço de venda, produção orientada ao mercado, gestão da produção e prospecção de novos mercados.

Quanto aos recursos intangíveis, pode-se identificar os humanos (conhecimentos técnicos e básicos de produção, proatividade, capacidades básicas de gerenciamento, relacionamento familiar, vontade de aprender, relacionamento interpessoal), os de inovação (adoção de novas técnicas de produção, cultivo de novos produtos, atendimento da demanda do consumidor) e os relacionados à reputação (imagem e qualidade dos produtos, confiança, aceitação na comunidade, fidelização dos consumidores, imagem do setor de produção de orgânicos).

Entendendo que a produção de orgânicos tem um longo e promissor caminho a trilhar, pode-se afirmar que o conhecimento dos produtores pesquisados é reforçado com a troca de experiências entre os seus pares, que compartilham do mesmo espaço de comercialização de seus produtos. Este tipo de organização ganha respaldo por meio da organização em instituições cooperativas que oferecem apoio, suporte, assistência técnica, conhecimento específico da produção, estratégias de mercado, entre tantos outros elementos importantes que contribuem para o sucesso individual e, especialmente, do grupo.

Por se tratar de pequenos produtores, importante observação respalda-se na capacidade da família rural de identificar e combinar a pauta de recursos tangíveis e intangíveis que valorizam e aprimoram o conhecimento explorado nas práticas de produção orgânica. De acordo com os dados, percebeu-se que a produção de orgânicos, entre tantas outras facetas que a integram, contribui para promoção da qualidade de vida para o meio rural, dignificando socialmente o produtor, valorizando a cultura e o saber 
resgatado de gerações. Este tipo de agricultura abrange uma alternativa econômica de estratégia de sobrevivência e desenvolvimento das famílias pesquisadas, além de contribuir na preservação da biodiversidade, utilizar rotação de culturas, entre outros.

De um lado, a produção orgânica apresenta-se como oportunidade aos pequenos agricultores, especialmente pelo potencial de desenvolvimento em pequenas extensões de terra. De outro lado, demanda a adoção de práticas de cultivo inovadoras que priorizem a qualidade dos produtos e a produtividade.

Diante dos desafios, pode-se entender o papel central das organizações cooperativas que congregam estes tipos de produtores, especialmente no que se refere à ampliação de assessoria técnica para a produção e comercialização, bem como a oferta de qualificação de técnicas de gestão administrativa e financeira aos produtores de orgânicos. Nessa dimensão, entende-se que, em determinado momentos configuram-se como um recursos intangível por promover a cooperação e intercooperação entre os sócios e, em outros, como um agente que viabiliza o acesso aos recursos tangíveis de produção e canais físicos de comercialização dos empreendimentos rurais familiares.

Outro aspecto que merece destaque é identificado pelos aspectos que limitam o desenvolvimento da produção e comercialização de produtos orgânicos. Nessa análise, é possível que eles estejam relacionados ao grau de escolaridade dos produtores entrevistados, à resistência de adotar novos modelos, tecnologias ou inovações na produção de orgânicos, bem como falta de iniciativa da própria cooperativa e grupo a que pertencem de pensarem estrategicamente seus negócios a partir dos recursos estratégicos que dispõem ou que podem ser adquiridos de outras fontes.

Um elemento na discussão dos recursos na produção de orgânicos centra-se na certificação. De um lado, tem-se um mercado consumidor cada vez mais propenso a priorizar a compra de produtos orgânicos e, de outro, o crescente número de produtores orgânicos que ampliam suas atividades produtivas, ou novos entrantes com produtos específicos para consumidores específicos. No centro dessa análise incluem-se os organismos ou instituições certificadoras, que têm um papel central nessa etapa da cadeia produtiva que. De acordo com Alves, Santos e Azevedo (2012), a lei brasileira abriu uma exceção à obrigatoriedade da certificação de produtos orgânicos para a venda direta aos consumidores finais por agricultores familiares, em que a credibilidade se assegura na responsabilidade solidária, que é uma declaração assinada por todos os membros do grupo que forma a Organização de Controle Social. Esse aspecto poderá converter-se em vantagem ou desvantagem, dependendo do interesse, profissionalismo, confiança, responsabilidade, ética, entre outros fatores que permeiam a reputação e interesse dos atores da cadeia de orgânicos.

\section{CONSIDERAÇÕES FINAIS}

O estudo teve como objetivo identificar os recursos tangíveis e intangíveis que se configuram como estratégicos na produção de orgânicos dos produtores da Feira Ecológica de Passo Fundo-RS. A partir dos dados levantados, pode-se compreender a relevância estratégica dos recursos tangíveis e intangíveis na decisão de produção orgânica. Tais recursos avançam na direção da consolidação do conhecimento adquirido através do tempo, bem como o crescimento e trabalho dedicado a este tipo de atividade produtiva. 
Conforme apresentado na discussão teórica, a VBR destaca que os recursos das empresas, quando bem utilizados, são responsáveis pela diferenciação das organizações em seus mercados, em relação aos concorrentes, fazendo com que obtenham resultados que garantam melhores desempenhos. Esta teoria, no entanto, possui sua base em pesquisas realizadas em empresas de médio e grande porte, principalmente as voltadas para atividades industriais. Diante deste fato, esta pesquisa dedicou-se a verificar se esta teoria também poderia ser aplicada a outras situações de organizações mais simples, em termos de estrutura, e que atuem somente no mercado local. Para tanto foram pesquisadas pequenas unidades de produção rural da agricultura familiar, que buscaram diferenciação produtiva e comercial por meio da produção orgânica, bem como passaram a se associar para organizar um espaço específico de interação e comercialização com seu público-alvo específico. Assim, este recorte ocorreu no caso concreto da feira de produtos agroecológicos da cidade de Passo Fundo, no Rio Grande do Sul.

De acordo com os resultados apresentados, verificou-se que a VBR pode sim ser aplicada ao contexto de pequenos produtores da agricultura familiar, que não só produzem de forma diferenciada (com a agricultura orgânica), como comercializam seus produtos em espaço específico para determinado nicho de mercado. Verificou-se que as organizações familiares possuem recursos tangíveis e intangíveis, em diferentes proporções e combinações, que as diferenciam das demais e que favorecem os resultados positivos. Um dos indicadores destes resultados está na ampliação das áreas destinadas à agricultura orgânica, diante da tradicional, como reflexo dos benefícios de comercialização e rentabilidade experimentados pelos produtores.

Adicionalmente, é importante destacar que os resultados não podem ser generalizados por não ter sido pesquisado o universo dos produtores alvos da pesquisa. E, por fim, pode-se sublinhar a complexidade do tema em análise e seus diferentes enfoques, configurando-se, numa perspectiva potencial de entendimento da participação dos recursos tangíveis e intangíveis explorados na produção de alimentos orgânicos em diferentes iniciativas no Brasil. Essa consideração baseia-se, especialmente, nas diferentes possibilidades de pesquisas futuras que o setor apresenta.

\section{REFERÊNCIAS}

ALVES, A. C. O.; SANTOS, A. L. S.; AZEVEDO, R. M. M. C. Agricultura orgânica no Brasil: sua trajetória para a certificação compulsória. Revista Brasileira de Agroecologia, v. 7, n. 2, p. 19-27, 2012.

BARBOSA, W. F.; SOUSA, E. P. Agricultura orgânica no Brasil: características e desafios. Revista de Economia e Tecnologia, v. 8, n. 4, p. 67-74, 2012.

BARDIN, L. Análise de conteúdo. Lisboa: Edições 70, 1997.

BARNEY, J. B. Firm Resources and Sustained Competitive Advantage. Journal of Management, v. 17, n. 1, p. 99-120, 1991.

BARNEY, J. B.; HESTERLY, W. S. Administração estratégica e vantagem competitiva: conceitos e casos. São Paulo: Pearson Prentice Hall, 2011.

BEGLEY, T. M.; BOYD, D. P. The Need for a Corporate Global Mind-Set. Mit Sloan Management Review, v. 44, n. 2, p. 25-32, 2003.

BRASIL. Decreto no 6.323, de 27 de dezembro de 2007. Regulamenta a Lei no 10.831, de 23 de dezembro de 2003, que dispõe sobre a agricultura orgânica, e dá outras providências. Brasília.

BRASIL. Ministério da Agricultura, Pecuária e Abastecimento (Mapa). Número de produtores orgânicos cresce 51,7\% em um ano. 2015a. Disponível em: http://www.agricultura.gov.br/comunicacao/noticias/2015/03/numero-de-produtores-organicos-cresce-51porcento-em-um-ano. Acesso em: 10 set. 2016. 
BRASIL. Portal Brasil. Economia e emprego: agricultura familiar produz 70\% dos alimentos consumidos por brasileiro. Com informações do Ministério do Desenvolvimento Agrário (MDA). 2015b. Disponível em: http://www.brasil.gov.br/economia-e-emprego/2015/07/agricultura-familiar-produz-70-dos-alimentos-consumidos-por-brasileiro. Acesso em: 13 set. 2016.

BUAINAIN, A. M.; ROMEIRO, A. R.; GUANZIROLI, C. Agricultura familiar e o novo mundo rural. Sociologias, V. 5, n. 10, 2003.

CASTRO JR., D. F. L.; SILVEIRA-MARTINS, E.; MIURA, M. N.; SILVA, M. P. P. O processo de formulação de estratégias e os recursos intangíveis da empresa: reflexões teóricas sobre esta relação. Revista Capital Científico, v. 13, n. 1, p. 150-164, 2015.

CEPAL; FAO; IICA. Situación y perspectivas de la agricultura familiar en América Latina y el Caribe. In: Perspectivas de la agricultura y del desarrollo rural en las Américas: una Mirada hacia America Latina y el Caribe. San Jose; Costa Rica: IICA, 2013.

D'ODORICO, P.; CARR, J., LAIO, F., RIDOLFI, L., VANDONI, S. Feeding humanity through global food trade. Earth's Future, v. 2, p. 458-469, 2014.

DIAS, V. V.; SCHULTZ, G.; SCHUSTER, M. S.; TALAMINI, E.; RÉVILLION, J. P. O mercado de alimentos orgânicos: um panorama quantitativo e qualitativo das publicações internacionais. Ambiente \& Sociedade, v. 18, n. 1, p. 161-182, 2015.

DIAS, V. V.; SALVATE BRASIL, N.; RÉVILLION, J. P.; SCHNEIDER, S. A importância da certificação nos circuitos curtos de alimentos orgânicos. Revista Espacios, v. 37, n. 3, p. 13-26, 2016.

FORTES, G. Venda de alimento orgânico aumenta até $40 \%$ no varejo. Folha de São Paulo. São Paulo, maio 2009. Disponível em: http://www1.folha.uol.com.br/fsp/dinheiro/fi1205200936.htm. Acesso em: 13 maio 2016.

GODOY, A. S. Pesquisa qualitativa: tipos fundamentais. RAE - Revista de Administração de Empresas, v. 35, n. 3, p. 21-29, 1995.

GRANDO, M. Z. Um retrato da agricultura familiar gaúcha. Porto Alegre: ,2011. 21 p. (Textos para Discussão Fundação de Economia e Estatística Siegfried Emanuel Heuser - FEE no 98).

GRANT, R. M. Resource-based theory of competitive advantage: implications for strategy formulation. California Management Review, v. 33, n. 3, p. 114-135, 1991.

HITT, M. A.; IRELAND, R. D.; HOSKISSON, R. E. Administração estratégica: competitividade e estratégia. São Paulo: Cengage Learning, 2011.

HOOLEY, G. J.; BRODERICK, A. J.; MÖLLER, K. Competitive positioning and the resource-based view of the firm. Journal of Strategic Marketing, v. 6, n. 2, p. 97-115, 1998.

IBGE. Instituto Brasileiro de Geografia e Estatística. Censo Agropecuário. Brasília, 2006.

IPD. Instituto de Promoção do Desenvolvimento. O mercado brasileiro de produtos orgânicos. Curitiba: Instituto de Promoção do Desenvolvimento, 2011.

IRELAND R. D.; HITT, M. A.; VAIDYANATH D. Managing strategic alliances to achieve a competitive advantage. Journal of Management, v. 2, p. 416-446, 2002.

KOR, Y. Y.; MAHONEY, J. T. Edith Penrose's (1959) Contributions to the Resource-based View of Strategic Management. Journal of Management Studies, v. 41, n. 1, p. 83-191, 2004.

MALHOTRA, N. Pesquisa de marketing. Porto Alegre: Bookman, 2001.

MAPA. Ministério da Agricultura, Pecuária e Abastecimentos. Secretaria de Desenvolvimento Agropecuário e Cooperativismo (ed.). O olho do consumidor. Brasília: Mapa, 2009. 34 p.

MORAES, M. D.; OLIVEIRA, N. A. M. Produção orgânica e agricultura familiar: obstáculos e oportunidades. Revista de Desenvolvimento Socioeconômico em Debate, v. 3, n. 1, p. 19-37, 2017.

ORGANICSNET. Manual de certificação de produtos orgânicos. Rio de Janeiro, 2016. Disponível em: http:// www.organicsnet.com.br/certificacao/manual-certificacao/. Acesso em: 29 out. 2016.

PENROSE, E. The theory of the growth of the firm. 4. ed. Oxford; New York: Oxford University Press, 2009. PEREIRA, P. R.; ABICHT, A. M.; CEOLIN, A. C.; CORREA, A. F.; SILVA, T. N. A subvenção de orgânicos no Brasil e na União Européia sob a ótica da Visão Baseada em Recursos. In: CONGRESSO DA SOCIEDADE BRASILEIRA DE ECONOMIA, ADMINISTRAÇÃO E SOCIOLOGIA RURAL, 46., 2008, Rio Branco-Acre. Disponível em: http://ageconsearch.umn.edu/bitstream/117275/2/315.pdf. Acesso em: 25 maio 2016.

PETERAF, M. A. The cornerstones of competitive advantage: a resource-based view. Strategic Management Journal, v. 14, n. 3, p. 179-191, 1993.

RABAIOLLI, J. A.; MIORIN, V. M. F. Valorização e competitividade das espacialidades rurais para além de suas concepções, papéis e controvérsias. In: ENCONTRO NACIONAL DE GEOGRAFIA AGRÁRIA, 21., 2012, Uberlândia. Anais [...]. Uberlândia: Universidade Federal de Uberlândia, 2012. 
SANTOS, G. Com novos hábitos, alimento orgânico ignora crise e segue em expansão. Folha de São Paulo. São Paulo, 2015. Disponível em: http://www1.folha.uol.com.br/mercado/2015/07/1661851-com-novos-habitos-alimento-organico-ignora-crise-e-segue-em-expansao.shtml. Acesso em: 28 maio 2016.

SCHNEIDER, S. A presença e as potencialidades da agricultura familiar na América Latina e no Caribe. $R e-$ des, v. 21, n. 3, p. 11-33, 2016.

SCHROEDER, R. G.; BATES, K. A.; JUNTTILA, M. A. A resource-based view of manufacturing strategy and the relationship to manufacturing performance. Strategic Management Journal, v. 23, p. 105-117, 2002.

SMITH, K. G.; COLLINS, C. J.; CLARK K. D. Existing knowledge, knowledge creation capability, and the rate of new product introduction in high-technology firms. Academy of Management Journal, v. 8, p. 346-357, 2005.

SOCIEDADE NACIONAL DA AGRICULTURA. Mercado brasileiro de orgânicos deve atingir 35\% de crescimento em 2014. 2014. Elaborado por: Primeira Página Assessoria de Comunicação e Eventos. Rio de Janeiro, 2014. Disponível em: http://sna.agr.br/mercado-brasileiro-de-organicos-deve-atingir-35-de-crescimento-em-2014/. Acesso em: 28 maio 2016.

SONG, M.; DROGE, C.; HANVANICH, S.; CALANTONE, R. Marketing and technology resource complementarity: an analysis of their interaction effect in two environmental contexts. Strategic Management Journal, v. 26, n. 3, p. 259-276, 2005.

SUBRAMANI, M. R.; VENKATRAMAN, N. V. Safeguarding investments in asymmetric interorganizational relationships: Theory and evidence. Academy of Management Journal, v. 46, n. 1, p. 46-62, 2003.

SUBRAMANI, M. R.; VENKATRAMAN, N. V. Safeguarding investments. Organizational Dynamics, v. 29, n. 3, p. 164-178, 2001.

VRIESMAN, A. K.; OKUYAMA, K. K.; ROCHA, C. H.; WEIRICH NETO, P. H. Assistência técnica e extensão rural para a certificação de produtos orgânicos da agricultura familiar. Revista Conexão UEPG, v. 8, n. 1, p. 138149, 2012.

WERNERFELT, B. A resource-based view of the firm. Strategic Management Journal, v. 5, n. 2, p. 171-180, 1984.

WINTER, A. G. Developing evolutionary theory for economics and management. In: SMITH, K. G.; HITT M. A. (ed.). Great minds in management: The process of theory development. Oxford, UK: Oxford University Press, 2005. p. 509-546.

ZEMOLIN, C. Análise das características do consumidor de produtos orgânicos nos municípios de Doutor Maurício Cardoso, Horizontina e Santa Rosa. 2012. 58 f. Trabalho de Conclusão de Curso (Graduação) Curso de Ciências Econômicas, Faculdade de Horizontina, Horizontina, 2012. 